\title{
De l'usage des victimes dans les stratégies politiques contemporaines
}

Guy Nicolas

\section{OpenEdition}

1 Journals

\section{Édition électronique}

URL : http://journals.openedition.org/conflits/531

DOI : $10.4000 /$ conflits.531

ISSN : 1777-5345

Éditeur :

CCLS - Centre d'études sur les conflits lilberté et sécurité, L'Harmattan

Édition imprimée

Date de publication : 6 décembre 1992

ISSN : 1157-996X

Référence électronique

Guy Nicolas, «De l'usage des victimes dans les stratégies politiques contemporaines », Cultures \& Conflits [En ligne], 08 | hiver 1992, mis en ligne le 07 janvier 2003, consulté le 30 mars 2021. URL: http://journals.openedition.org/conflits/531 ; DOI : https://doi.org/10.4000/conflits.531

Ce document a été généré automatiquement le 30 mars 2021.

Creative Commons License 


\title{
De l'usage des victimes dans les stratégies politiques contemporaines
}

\author{
Guy Nicolas
}

A un moment de l'histoire de l'humanité où il paraissait légitime de célébrer l'avènement d'un ordre planétaire nouveau, sous les étendards des Droits de l'Homme et d'une solidarité universelle, la multiplication d'explosions de violences associées à des mobilisations communautaires ouvre une problématique inattendue: de la Kirghizie à l'Afrique Australe, de l'Indonésie aux USA, du Cachemire à la Bosnie, les amoncellements de victimes font planer sur le rêve humanitaire le spectre d'un retour des passions sacrificielles que l'on avait pu croire conjurées.

Les violences en question diffèrent des dérives anomiques qui se développent dans les interstices des sociétés "policées". Elles émanent, en effet de communautés réaffirmant les prétentions des nations les plus antiques à fonder leur existence ou leur survie sur le sacrifice volontaire de leurs membres, sacralisé par une identification aux héros de mythes originels. Le temps des martyrs est de retour et, avec lui, celui des passions victimaires, dont l'usage est de plus en plus oublié par les Etats établis.

Toutefois, ces processus qui réactivent des modèles millénaires se trouvent aujourd'hui infléchis par leur inscription dans un espace de mondialisation, de médiatisation et "d'humanitarisation" qui en modifie radicalement la structure en les positionnant sur une scène nouvelle, marquée par l'irruption de tiers partenaires, en principe indifférents à l'origine aux passions communautaires des parties en confrontation. L'apparition de ces derniers en modifie radicalement le cours : ce tiers-parti spectateur, arbitre, intervenant éventuel se détermine ici sur des bases de "compassion" pour les victimes. Il s'agit dès lors pour les parties engagées dans un conflit local de se placer sur un marché victimaire mettant en jeu des cotations quantitatives concernant le nombre de morts, des blessés, des sans-abri, des affamés, des exilés. Pour accéder à une cote efficiente sur un tel marché, une communauté se doit au minimum d'atteindre un certain seuil de victimisation, seuil toujours fluctuant et toujours plus élevé, du fait de 
la concurrence des entreprises victimaires et de la limitation des capacités d'intervention des tiers consommateurs de compassion, contraints de maximiser leurs choix. Il lui faut donc produire des victimes, en l'occurrence des victimes qui soient les siennes et non celles de ses antagonistes, lesquels pourraient se réclamer de leur propre victimisation pour réduire ses prétentions et promouvoir leur propre cause.

Du fait de cette dérive, les martyrs se trouvent mués en valeurs utiles pour placer leurs entreprises communautaires sur ce marché. Or, celui-ci est soumis aux mêmes règles, lois et impératifs de promotion que tout autre. En particulier, la cote victimaire d'une communauté mobilisée implique l'intervention de différents prestataires de services : institutions médiatiques, sans lesquelles la production victimaire peut être inefficiente, elles-mêmes soumises aux impératifs d'autres marchés, organes gestionnaires d'action humanitaire, démarcheurs de consommateurs de compassion victimaire, productrice d'une demande humanitaire, de dons, de public médiatique, de sponsors financiers ou électoraux ... Des stratégies nouvelles se mettent ainsi en place qui, toutes, débouchent sur l'accumulations de tragédies gérées de façon plus ou moins rationnelles. Toutefois, ces processus risquent de provoquer une saturation du marché évoqué, provoquant une désinflation de ce dernier.

Nous tenterons dans ces lignes d'esquisser les contours de ces errements dans un souci de prise en compte d'un secteur du champ de la violence jusqu'ici quelque peu négligé par les analystes et, au delà, du phénomène de "renouveau politique", au sens, un peu oublié, de gestion des affaires publiques communautaires, nationales ou internationales (la politique), mais encore et surtout de l'acte fondateur de toute polis, c'est à dire l'acceptation par ses membres de l'éventualité de leur "sacrifice suprême", condition indispensable à son édification, à sa survie, à sa promotion.

Du désenchantement des passions victimaires à leur résurgence

Une certaine vision des sociétés "primitives", d'inspiration évolutionniste, a conduit à un renvoi du principe sacrificiel aux commencements de l'histoire. Dans cette perspective, l'accent a été porté sur les mythes fondateurs des sociétés de tradition et les rites de commémoration de sacrifices fondateurs, ceux-ci comportant l'immolation de victimes émissaires ${ }^{1}$. Ces usages ont fait oublier que la quasi-totalité de ces sociétés devaient, jusqu'à présent, défendre leur survie les armes à la main et, pour ce faire, susciter chez leurs membres l'acceptation de l'éventualité de l'offrande de leur propre vie. Sans doute croyaient-elles que les ancêtres, les masques ou les dieux combattaient à leurs côtés, en échange du sacrifice renouvelé de victimes. Mais leurs membres devaient être prêts à se sacrifier pour elles. La victime consentante se trouvait récompensée dans l'Au-delà. Mais elle l'était également par l'échange d'une existence quotidienne, profane, contre une immortalité de gloire dans la mémoire des survivants et descendants. Elle se trouvait conditionnée à cette fin héroïque par le discours sacrificiel associé à sa socialisation de base, mythes et légendes véhiculant des modèles offerts à l'identification du sujet.

Les confrontations traditionnelles étaient soumises, par ailleurs, aux lois de l'échange réversif, qui reposait sur le principe d'un équilibrage des victimes. Cette loi de vendetta relevait d'une logique bien plus vaste, qui gouvernait également le jeu des unions matrimoniales, des fêtes, des échanges de biens ou les rituels ${ }^{2}$. La guerre résultait le plus souvent de l'obligation de venger une victime. Elle s'arrêtait quand le nombre des victimes compensatrices s'équilibrait, provisoirement. Guerre et paix reposaient ainsi sur un jeu de comptage et de réversion équilibré. 
Ces dispositifs ne fonctionnèrent plus dans le cas des grandes invasions, des mouvements hégémoniques liés au développement des empires, de l'esclavage, des "guerres saintes" et autres "croisades". En ce cas, le groupe agresseur multiplia sans compter les victimes dans le but de détruire ou de soumettre l'agressé par la terreur. La communauté agressée ripostait alors par des massacres dissuasifs ou des opérations suicidaires destinées à éviter la dite soumission, dans la mesure où elle pouvait compter sur l'adhésion de ses membres à tel sacrifice.

En dépouillant les communautés traditionnelles de leurs prétentions à gérer la destinée de leurs membres, l'Etat moderne a dévalorisé à son profit cet ordre victimaire antérieur³. S'identifiant à l'émergence de la raison triomphant du pathos médiéval, barbare ou sauvage, l'Etat monarchique a monopolisé le Droit universel, puis la substitution du Prince agissant selon son "bon plaisir" par l'Etat moderne tirant sa légitimité d'une délégation du peuple souverain a favorisé l'émergence du sujet individuel, libre de ses choix. Ce "citoyen" a néanmoins reconnu à son Etat un monopole de gestion de la violence à l'intérieur de son territoire, dans le cadre du droit établi et surtout le droit de lui imposer, au besoin par la force, l'offrande de sa vie en cas de guerre : "mourir pour la patrie est le sort le plus beau". L'Etat sacrificateur gère le "martyre" éventuel de ses mandants et défenseurs, en entretient le culte, commémore les grands héros, honore les victimes exemplaires. En temps de paix, par contre, il cède le pouvoir d'immoler les citoyens contrevenants à ses lois au pouvoir judiciaire.

Aujourd'hui cependant, la conscription devient suspecte. La peine de mort est condamnée. Toute violence légale est mise en question. Les sciences sociales exonèrent les coupables. La mise en place d'instances d'arbitrages supra-étatiques et d'un Droit international servi par des institutions dépouillées de tout enracinement communautaire, imposent un état général de non-belligérance. Les Etats se soumettent à l'arbitrage des tribunaux internationaux et accordent leurs législations au Droit universel d'un homme abstrait. Dans un monde où chaque sujet peut recourir à des arbitrages supérieurs pour faire valoir sa "différence", la figure du "martyr" communautaire perd de sa puissance de fascination. Les dernières confrontations interétatiques suscitent l'opprobre général, celui-ci légitimant des interventions répressives dont l'efficience est d'ailleurs évaluée, en cas d'usage de la force, à leur caractère "propre", c'est à dire a-victimaire.

Dans ce monde aseptisé, le messianisme marxiste a proposé une alternative fondée sur le sacrifice militant au service du prolétariat martyr, porteur d'un homme universel nouveau, remettant à l'honneur la passion victimaire. Le militant convaincu, désaliéné de l'idéologie petite-bourgeoise du Moi individuel, acceptait de se sacrifier "pour le parti" au point, dans certains cas, de se renier lui-même.

Le service de l'histoire justifiait la victimisation de peuples entiers, supportait la menace d'une apocalypse planétaire. L'effondrement de cette vision du monde, et le triomphe consécutif du libéralisme ont paru ouvrir la voie au déploiement d'un nouvel ordre international excluant toute victimisation tandis que les producteurs de victimes étaient justiciables de tribunaux spéciaux sanctionnant les "crimes contre l'humanité", le consentement d'un sujet ou d'une communauté au "martyre" étant perçu comme un vestige d'un âge barbare ou une dérive pathologique, sous le signe du masochisme ou du désir de mort. 
Seules demeuraient actives, aux franges de la société "civilisée", des mouvances anomiques s'affirmant victimisées par les institutions et revendiquant l'usage d'une violence protestataire "libre". Dans un contexte mouvant où certains Etats pouvaient encore menacer leurs voisins, les appels victimaires conservaient une certaine actualité au sein des cadres nationaux. Dans la plupart des cas, cependant, les Etats ont renoncé à mobiliser l'ensemble de leurs citoyens. Seuls des corps volontaires, minoritaires, voués par vocation à la violence, entretiennent la flamme sacrificielle, constituant des sanctuaires de victimisation potentielle où les Etats peuvent puiser en cas de nécessité. Les sociétés prétoriennes, héritières des noblesses d'épée exaltées par Hegel pour ce fait $^{4}$

, se fondent en effet sur le choix d'un destin marqué par l'éventualité d'une mort librement acceptée. C'est cette vocation au martyre glorieux qui est d'ailleurs invoquée par les auteurs des coups d'Etats militaires, présentés comme la seule issue pour arracher une société victimisée par des dirigeants corrompus à un chaos générateur de violences plus graves. Ayant fait don de leur vie à la nation, les «rédempteurs » se trouvent légitimés par leur statut sacrificiel, à condition de n'en pas déchoir. C'est parce qu'ils ont choisi l'éventualité de leur mort au combat qu'ils peuvent impunément utiliser la violence pour réduire des résistances éventuelles. C'est sur de tels corps victimaires que les institutions internationales s'appuient d'ailleurs aujourd'hui pour gérer des crises comportant des sacrifices.

Les stratégies victimaires des mouvances anomiques se justifiant de leur propre victimisation par l'Etat, les forces de l'ordre ou la société, quant à elles, pratiquent pour revendiquer un droit de victimisation un usage instrumental des victimes «bavures", fondant ou justifiant ainsi leur position. Le bandit d'honneur, la bande de quartier qui se mobilise pour venger un "martyr", la foule "en colère" s'identifiant à une victime exemplaire, s'insèrent dans les failles d'un ordre ambigu. En mettant en scène sa ou ses victimes, la constellation anomique se pose comme témoin (marturos) de la faute des détenteurs du Droit et désacralise son droit à monopoliser la violence "légitime" ${ }^{5}$. Mais ces temps de mobilisation débouchent rarement sur des constructions communautaires, des "nations" durables faute de pouvoir édifier un modèle victimaire positif, étayé par des mythes sacrificiels fondateurs.

Le retour des martyrs

Tout autre est le cas des résurgences communautaires contemporaines retrouvant les sentiers des antiques polis victimes du "désenchantement" moderne. En l'occurrence, il ne s'agit pas de Nations-Etats établies, dont la légitimité, la souveraineté et le droit de gérer la violence sont garantis par les institutions internationales dont elles sont membres de droit. Nous avons à faire à des Nations sans Etat s'estimant victimisées au sein des cadres stato-nationaux en question et revendiquant leur autonomie. Ces courants se développent dans les aires d'implosion de l'institution étatique : ex URSS, Europe de l'Est, Etats du Tiers Monde, mais aussi dans les banlieues et autres marges des sociétés les plus cohérentes. Ils se manifestent également dans le cadre d'un "retour du religieux" à caractère nationalitaire. De vieilles solidarités éclatées que l'on avait cru évanouies à jamais se réveillent, revendiquant un droit de victimisation légitime sur leurs membres, librement accepté par les participants. Ces mouvements sont animés et parfois suscités par des "entrepreneurs identitaires" qui s'emploient à communiquer leur foi communautariste à des entourages au départ étrangers à cette perspective, spéculant sur des situations de victimisation émanant d'adversaires plus 
avancés dans ce processus. Ces meneurs se posent en représentants charismatiques de leurs "peuples" et de ce fait comme les détenteurs du droit sacré de décider du sacrifice éventuel de leurs mandants. De telles mobilisations sont parfois difficiles à provoquer, compte tenu des réticences des sujets interpellés à accepter une telle extrémité dans un monde où l'homme collectif d'antan est dévalué et où chaque sujet est sollicité par des polarités identitaires concurrentes, soutenant des solidarités communautaires contradictoires (polarités nationale, ethnique, régionale, socio-économique, confessionnelle, idéologique, clientéliste, sexuelle, politique...).

Il faut toutes les ressources d'un "management humain" manipulant à la fois les vieux mythes sacrificiels hérités du passé, les imaginaires modernes, des processus d'identification, d'imitation, de contagion ou de pression collective pour que le sujet des droits de l'Homme universel s'abandonne à la passion victimaire. La psychologie du tragique, un temps détrônée par celle du roman, reprend ses droits. Toutefois, de tels processus n'ont abouti jusqu'ici à l'instauration de logiques sacrificielles durables que dans deux secteurs privilégiés, à savoir la "nation-ethnie" et la communauté confessionnelle. Usages ethno-nationalitaires des victimes La montée contemporaine des mobilisations d'"ethnies", "nations sans Etats", ou "minorités socioculturelles" a d'autant plus surpris que, du fait de la confiscation du pouvoir victimaire par l'Etat moderne, l'opinion s'était habituée à une approche pacifique, "culturelle", du fait ethnique, accréditée par diverses "sciences humaines", ce glissement s'est trouvé accentué par l'extension de l'usage anglo-saxon, et notamment nord-américain, du concept d'"ethnie", employé pour désigner les "minorités" les plus disparates (noirs, indiens, immigrés, latino-américains, femmes, homosexuels...), dans le cadre d'une catégorie dont l'aspect victimaire de fondation est essentiellement négatif. Mais la multiplication des mouvements d'affirmation "identitaire" se réclamant d'héritages nationaux transcendants et brimés et l'accumulation d'holocaustes qui en résulte, ont forcé l'opinion à reconsidérer la dénégation initiale du caractère politique de telles mobilisations . Devant l'échec des solutions de type fédéraliste, fondées sur le modèle d'une mosaïque "culturelle" et la faveur dont bénéficie au sein de l'opinion publique contemporaine la cause des "peuples opprimés", il a bien fallu admettre que des "nations" oubliées continuaient à exister et à mettre en question des partages statonationaux proclamés définitifs et intangibles.

Dans un premier temps, cependant, et conformément à la dépréciation du fondement sacrificiel des communautés politiques, les nouveaux holocaustes ont été appréhendés sous leur aspect agressif. En l'occurrence, les victimes recensées étaient elles, "innocentes" d'agressions venant de l'extérieur des communautés persécutées ${ }^{6}$. Cette approche occultait le fait fondamental que, pour que de telles dérives se produisent, il convenait au préalable que les "peuples agressifs" se polarisent sur des causes communautaires et, que leurs membres consentent à cet effet à engager leur propre vie dans des entreprises souvent suicidaires au départ. En d'autres termes, il convenait que ces sujets soient possédés par quelque passion victimaire ne correspondant pas seulement à des gestes de désespoir ou de colère, ou à tout autre processus d'imitation, de contagion ou d'identification à un leader. Sans victime volontaire, pas de mobilisation totalitaire et peu de victimes extérieures ${ }^{7} . . .0 r$, les nations-ethnies "martyres" ont l'avantage d'offrir à leurs membres et aux minorités activistes qui s'emploient à les mobiliser tout un corpus de mythes, de rituels victimaires constamment revivifié par les cérémonies commémoratives, les récits éducatifs, le 
folklore : éléments essentiels de la socialisation de l'enfant, exaltant les figures de "martyrs" offertes à l'identification des héritiers.

Un autre avantage de ce cadre social est de se fonder sur un imaginaire de durée étendue, voire d'éternité, basé sur la croyance selon laquelle les martyrs d'antan se réincarnent symboliquement de manière quasi-biologique dans ceux d'aujourd'hui, lesquels transmettront cet héritage à leurs descendants pour que, de génération en génération, de victime consentante en victime consentante, la lignée se perpétue et avec elle l'être collectif "éternel" qu'elle constitue. La victime volontaire entre dans le panthéon de la communauté, laquelle lui offre en échange une gloire "éternelle". C'est au prix de cette gloire flamboyante que le sujet moderne en vient à consentir son autosacrifice. A l'encontre des réactions des foules "en colère", de tels processus ne sont ni automatiques, ni immédiats. Il faut y convertir des sujets réticents, invités à privilégier l'identité ethno-nationalitaire en question sur toute autre, au prix de déchirements souvent cruels, à se solidariser de leurs coparticipants, puis à se mobiliser dans le cadre d'opérations de plus en plus actives et mortelles. A cet effet, il est souvent indispensable pour les meneurs de disposer de premiers "martyrs", lesquels incarnent les grandes figures mythiques et suscitent des processus d'identification, ainsi que des réaction vindicatives à l'encontre de leurs bourreaux. Or, ces victimes ne peuvent être produites, en principe, que par l'adversaire désigné comme persécuteur: l'autre communauté, l'Etat ou ses forces de répression. Ce sont souvent les brutalités de cellesci, activées par les provocations des groupes activistes dont l'objectif est la production des victimes de l'Autre, que celles des victimes propres à leur communauté, qui provoquent l'engagement des "minorités silencieuses". Un cycle de provocation/ répression peut alors s'engager, soutenu par la passion victimaire des combattants. L'Autre dominateur - et notamment l'Etat dont le discours "légitime" nie la portée nationalitaire de ce type de mouvement, le réduit à des réactions momentanées, passibles de traitements pacifiques ou à l'influence de mauvais citoyens ou d'étrangers cherchant à déstabiliser la nation - peut également s'employer à contrôler l'ardeur victimaire de ses agents. En privant les agitateurs du ressort des identifications victimaires immédiates, il peut ainsi espérer les isoler, voire les discréditer, pour peu que ceux-ci fassent preuve d'une ardeur victimaire réduite en ce qui les concerne. Dans un tel cas, leurs stratégies sacrificielles peuvent alors se retourner contre eux. Par contre, toute répression aveugle peut entraîner des réaction de solidarité de la part de fractions de la communauté rebelle peu impliquées à l'origine dans ces processus.

Usages victimaires des communautés politico-confessionnelles

Il existe un second champ d'application du "retour des martyrs" un domaine pourtant considéré dans la perspective laïque moderne comme particulièrement impropre à de telles stratégies, dans la mesure où la "religion" est définie comme un domaine "privé" par essence, fondée sur un rapport direct du croyant à l'Au-delà. Les grandes religions se fondent, pour la plupart, sur une figure sacrificielle fondamentale, valorisent leurs martyrs et n'ont pas toujours fait preuve par le passé d'un aussi grand détachement qu'aujourd'hui vis à vis du domaine communautaire, social ou politique. Mais en dépit de quelques incursions de type clérical, parfois ambiguës, dans le domaine "séculier" on n'attend plus d'elles, aujourd'hui un recours aux "guerres saintes" d'antan.

Cette perspectives se heurte aujourd'hui à l'évidence de mobilisations politicoconfessionnelles fondées sur les mêmes stratégies victimaires que les mouvements 
ethno-nationalitaires, avec lesquelles elles se confondent souvent et auxquels elles peuvent constituer des alternatives.

Les courants contemporains de "revanche de Dieu" s'inscrivent en effet, dans une sphère de recommunautarisation ambiguë, débouchant sur des représentations collectives indubitablement politiques, qu'il s'agisse de mouvement de "rejudaïsation", de "réhindouisation", de "rechristianisation" ou de "réislamisation"... En principe, de tels mouvements relèvent $d u$ cadre des rapports entretenus par les communautés confessionnelles ou les clergés qui prétendent parler en leur nom et l'Etat moderne. Mais certaines communautés en viennent à s'opposer à leurs rivales de façon violente et s'érigent en contre-nations, selon le modèle de la partition indo-pakistanaise. D'autres se mobilisent dans le but de substituer aux structures étatiques en place de nouveaux ensembles nationalo-confessionnels. D'autres enfin, s'estimant opprimées par les Etats ou les majorités des nations où elles s'inscrivent se dressent les armes à la main contre leurs "persécuteurs", fictifs ou réels. Des minorités activistes plus ou moins enracinées dans des terreaux ethno-nationalitaires culturalo-cultuels s'emploient à susciter chez leurs coreligionnaires des attitudes communautaristes à caractère politique et bientôt violent. Ces "appels" débouchent sur la production de passions victimaires exaspérées par le rappel des martyrs d'antan, proposées comme pôles d'identification.

Des Indes à l'Irlande et du Soudan au Caucase, les exemples de telles dérives se multiplient, renouvelant les holocaustes inter ou intra-confessionels d'un passé plus ou moins récent. De telles positions peuvent être expliquées par des situations modernes tout autant que par l'impact d'imaginaires séculaires, les effets du "désenchantement" de la modernité, la crise identitaire du monde contemporain, les stratégies d'activistes en quête de pouvoir... Mais leur force mobilisatrice est étroitement liée à l'impact du modèle sacrificiel véhiculé par les patrimoines religieux.

L'ambiguïté de ce type de mobilisation par rapport aux courants ethno-nationalitaires est que, tandis que ces derniers placent le sujet appelé face au jugement de son "peuple", conçu en terme de sujet collectif associant ancêtres, individus vivants et générations à venir, celui-ci le traduit devant une divinité dont les desseins ne sont pas nécessairement communautaires. Cette divinité peut être réputée sensible au sacrifice du fidèle. L'auto-sacrifice du martyr est donc non seulement une offrande agréable à celle-ci, mais il constitue encore la voie royale par laquelle le croyant peut accéder à une éternité dont l'éclat éclipse les avantages d'une vie terrestre dévalorisée et suspendue au bon vouloir de l'Au-delà. Il arrache le "pêcheur" à l'angoisse du jugement dernier et à la crainte de sombrer, pour certaines religions, dans un univers de persécution éternelle. Par le court-circuit victimaire, le croyant "fanatisé" insouciant de sa vie, achète à bon compte une paix et un bonheur éternels.

On n'oubliera pas, cependant, que ce dispositif proprement religieux débouche sur une dimension communautaire, dans la mesure où le sacrifice du "martyr" est utile à l'édification, au maintien, à l'expansion de son église, de son oumma, incarnée en une communauté dont la majorité des membres hésite à faire un tel saut dans l'inconnu, si glorieux et apaisant soit-il, ou qui est vouée par destination messianique à assurer le règne terrestre de la divinité. Toute communauté a tendance à se constituer en un bloc ethno-nationalitaire. La position du converti individuel, plus sensible à la gestion de son salut, diffère souvent ici de celle du fidèle d'une communauté ancienne, dont la foi lui a été communiquée dès son enfance. Or, une telle communauté ne se constitue qu'en 
exaltant un sacrifice originel, le geste des anciens martyrs, l'éventualité d'un sacrifice "pour la foi" et en célébrant des rituels qui actualisent ces moments et y associent les vivants. En ce sens, elle diffère peu des lignées ethno-nationalitaires, compte tenu du fait que les peuples anciens étaient des ensembles à la fois cultuels et politiques.

Dans les sociétés demeurées attachées à des cultes ancestraux, les vieux référents sacrificiels conservent une dimension politique latente, toujours susceptible d'être réactivés, ainsi qu'on le constate en Inde actuellement, dans le cadre du mouvement d'Ayodhya, où une religion identifiée à un pacifisme fondamental sombre dans une production victimaire génératrice de massacres en chaîne. En ce qui concerne les cultes monothéistes, le judaïsme, devenu, après le suicide collectif de Massada, la victime par excellence des populations au sein desquelles s'est effectuée la diaspora et dont l'existence en tant que communauté s'est fondée sur la perpétuation d'un auto-sacrifice symbolique, au prix d'une passivité absolue face à la victimisation nazie, a retrouvé dans le mouvement sioniste le ferment d'une affirmation politique étayée sur une passion victimaire de fondement, elle même génératrice de celle du peuple palestinien. Pour les fondateurs d'Israël, le sacrifice accepté de leur vie rachèterait la passivité des victimes passées. Aujourd'hui encore, c'est l'éventualité constante d'un nouvel holocauste qui fonde la légitimité des productions victimaires affectant les populations des territoires occupés. Même étrangère à ces positions sacrificielles, au grand dam des fondamentalistes, la diaspora ne se réassure pas moins sur celles-ci.

Quant à la chrétienté, si elle se présente aujourd'hui, en Occident tout au moins, comme étrangère à toute détermination victimisante, celle-ci étant résolue par le sacrifice du Dieu martyr auquel participe tout fidèle dans le cadre du "Saint Sacrifice" de la messe, elle n'en vénère pas moins ses martyrs, anciens et contemporains, dont le sang est "une semence de chrétiens". Tout chrétien est susceptible d'affronter le martyre pour témoigner de sa foi face à un Autre persécuteur. Et c'est en partie parce qu'elle témoigne d'un courant d'indifférence à l'égard de l'identification sacrificielle que le retrait cultuel est perçu comme un danger par certains clergés. Justifiée par le modèle de la passion christique et le message d'amour diffusé par l'église ("si on te frappe sur une joue..."), la passion victimaire est présentée comme l'arme absolue de cette foi en cas de confrontation avec des adversaires agressifs, lesquels peuvent d'ailleurs être les membres d'églises dissidentes, comme il en fut des réformés et comme il peut en être des catholiques en Pologne, ou des orthodoxes au sein de l'ex Union soviétique ou de l'ex Yougoslavie. Dans ces pays, les entreprises de la "nouvelle évangélisation" visent d'ailleurs davantage à reconstituer des chrétientés combatives dans la passion victimaire de leurs membres qu'à diffuser un message d'amour !

$C^{\prime}$ est au sein du secteur musulman, soumis à des courants de politisation se réclamant de modèles fondés sur la non-séparation du politique et du religieux, au demeurant avalisé par des spécialistes occidentaux de l'islam, que la dimension sacrificielle est aujourd'hui la plus exaltée. Ces courants véhiculent l'imaginaire mobilisateur d'un "jihad" entendu dans son acceptation la plus agressive, ainsi que du martyre, l'un et l'autre étant étroitement mêlés. Cette position contraste avec celle des mouvements mystiques soufis, piétistes ou simplement classiques. Ils s'appuient sur un mouvement planétaire de "réislamisation" appelant à la construction d'une "nation" islamique universelle (oumma). Ils bénéficient de l'appui de pays musulmans engagés dans des stratégies géopolitiques mobilisatrices, des institutions internationales vouées au service de la cause islamique et à la défense des "minorités" musulmanes persécutées des Philippines à l'Amérique du Nord ou de la Chine à la Bosnie, et de l'impulsion de 
réseaux d'activistes internationaux capables de déplacer des "combattants de la foi", voire de produire des terroristes kamikazes.

Le monde musulman est ainsi traversé par des courants bénéficiant d'appuis logistiques ou militaires et de solidarités mondiales. Or l'attention portée par l'opinion politique mondiale, notamment occidentale, aux productions victimaires extérieures de cette mouvance a fait souvent oublier que les mobilisations qu'elle engendre, reposent avant tout sur la vocation au martyre de leurs participants.

C'est au sein de l'ensemble chi'ite, édifié sur le martyr des imams descendant du calife Ali, et notamment de son fils Husein, assassiné par son rival Yazid à Karbala, le 10 octobre 680 , que le culte du sacrifice est le plus vivant ${ }^{9}$. Chaque année, l'anniversaire de la tragédie de Karbala est célébrée par des foules en deuil, dans un concert de flagellations publiques. Cette vision victimaire a été revivifiée par un clergé dressé contre un régime impie assimilé à celui du bourreau Yazid, débouchant sur la "révolution islamique" de 1979 et l'édification d'une République islamique porteuse d'un projet de réislamisation armée d'extension planétaire. Cette politique a remis en vigueur le modèle du martyr rédempteur, bientôt actualisé par les islamistes libanais ou afghans et surtout par les massacres résultant du conflit Irak-Iran (1980-1988)), au cours desquels des dizaines de milliers de combattants, notamment des enfants, ont été engagés dans des productions victimaires massives. Un des principaux promoteurs de ce mouvement, Ali Shari'ati a avancé une idéologie qui substitue au deuil de Karbala une conception plus active et exaltante, fondée sur l'identification du martyr contemporain à l'imam Husein. Ce massacre ne doit pas être perçu comme un événement passé dont on porte le deuil mais comme un idéal présent. Dans cette vision pathétique, la mort au combat est exaltée par opposition à la mort "noire" subie et non choisie, qui prend par surprise. Le militant lui choisit sa mort. Il sait pourquoi il meurt. Il convient de retrouver la "tradition de mourir" en s'offrant comme sacrifice. Cet acte libre et glorieux ne saurait être ravalé au rang des actes utilitaires. De même que l'imam Husein est mort vaincu, le combattant ne doit pas viser quelque efficacité en soi, Dieu étant le maitre de l'issue ${ }^{10}$. Une telle vision débouche sur l'acte kamikaze, selon la logique propre au domaine religieux, pour laquelle, selon G. Bataille ${ }^{11}$

, "le sacrifice arrache l'individu du monde de l'utilité". D'où la fascination qu'il exerce sur un sujet désenchanté de l'existence du quotidien. Les événements qui ont suivi ont montré qu'une telle mystique de la mort n'est pas sans attrait ni utilité entre les mains de stratèges absolutistes.

Le courant sunnite n'a cessé, de son côté d'inspirer des mouvements de "jihad", messianiques ou non, fondés, eux aussi, sur la fascination du martyr, le croyant mort les armes à la main étant censé entrer directement au paradis. Pour certains groupes radicaux contemporains, comme le groupe "Al Jihad", responsable de l'assassinat du président égyptien Sadate, en octobre 1981, la "guerre sainte" était un "impératif occulté par les docteurs au service d'un pouvoir païen (jahili)" ${ }^{12}$. Le procès de ses membres et des responsables des massacres consécutifs de chrétiens d'Assiout, en décembre 1982, a vu ces sacrifiés volontaires exalter la peine suprême qui les menaçait et manifester leur joie de mourir en martyrs ${ }^{13}$. $C^{\prime}$ 'est également dans un tel but que les rescapés du "jihad" tout à fait hétérodoxe perpétré par les adeptes de la secte nigériane de Maitatsine, de 1982 à 1985, contre les forces de l'ordre de ce pays, après avoir manifesté un "fanatisme responsable de près d'une dizaine de milliers de morts", refusèrent d'être soignés ${ }^{14}$. C'est aussi au nom d'un sacrifice librement accepté que les 
partisans du messie sunnite Mohammed ben Abdallah se sont enfermés avec lui dans la grande mosquée de la Mecque, en novembre 1979, résistant jusqu'à la mort aux assauts de forces armées, notamment étrangères, au prix de plusieurs centaines de victimes. C'est une même passion qui anime les commandos "afghans" intervenant aujourd'hui en Algérie ou en Bosnie, au service d'un "islamisme radical" dans lequel un islamisant tel que Bruno Etienne a discerné l'effet d'une vision apocalyptique centrée sur l'attente de la fin des temps, que des "impatients" tentent d'accélérer, en se sacrifiant euxmêmes volontairement ${ }^{15}$.

En réalité, la passion victimaire, ou, pour reprendre l'expression de cet analyste, l'"ivresse de la mort" n'a jusqu'ici possédé qu'une minorité d'activistes et l'"islam politique" s'efface devant un "néo-fondamentalisme" moins héroïque ${ }^{16}$. Le "fanatisme" est, et demeure, un phénomène de foule, davantage que de société politique. Par contre, le chantage à la terreur a pu, en certains cas, favoriser des politiques de "purification confessionnelle" se traduisant par l'exode forcée des "impurs": juifs, chrétiens, "idolâtres" ou musulmanes "infidèles". L'une des applications les plus décisives d'une stratégie de provocation "à la vie, à la mort" est la constitution d'espaces autonomes dont l'instauration et la survie dépendent des capacités victimaires des communautés qui se le disputent.

Une des caractéristiques des conflits évoqués dans ces lignes est toutefois d'être des confrontations de "basse intensité". Il ne s'agit pas, le plus souvent, de véritables guerres mais d'affrontements entre un Etat et une "société civile" dans lesquels le premier s'efforce de réduire sa violence à des fins de séduction des "majorités silencieuses" ou des "rebelles", de respectabilité, en tant qu'Etat ou de légitimation de son action auprès de son opinion nationale entretenue dans l'idée que la répression n'est qu'une action de police, mais partagée quant à l'opportunité de l'usage d'une violence massive, tandis que ses adversaires s'emploient à retenir leur propre violence en deçà d'une ligne critique en vue de conserver leur statut victimaire ou d'éviter leur destruction.

Emergence d'un tiers-ordre "humanitaire" et nouvelles stratégies victimaires

Les renouveaux sacrificiels que nous venons d'évoquer s'inscrivent dans le cadre de problématiques à la fois insulaires et binaires dans lesquelles les "martyrs" viennent vivifier des communautés politiques, favoriser leur consolidation, susciter une passion victimaire propice à leur mobilisation, leur permettant d'affronter des communautés rivales fondées sur les mêmes bases, ou un Etat despote. Or, ce cas de figure subit aujourd'hui des infléchissements dus à l'entrée en scène d'un tiers-pouvoir détenteur de capacités d'intervention supérieures, à priori étranger aux causes en jeu, mais susceptible de s'impliquer dans les conflits locaux en tant qu'arbitre, juge ou partieprenante. Dans cette nouvelle mise en scène triangulaire, la partie dominatrice éventuelle peut se trouver conduite à réduire ses agissements répressifs, tandis que la partie dominée est confortée dans ses aspirations, secourue, voire assistée dans sa politique d'indépendance. Ce tiers-ordre en pleine élaboration se fonde sur une opinion sensible à toute tragédie et capable de modifier le cours des événements par ses pressions sur les Etats, Institutions internationales ou réseaux privés d'ingérence. Toutefois la capacité de compassion de cette opinion doit être activée ou ciblée sur telle ou telle situation de victimisation pour être efficace.

La mise en place de l'appareillage évoqué résulte de la convergence de différentes dynamiques. Une première dynamique s'inscrit dans le cadre des processus de 
mondialisation qui ne cessent de se développer du fait du déploiement des échanges, des communications, des techniques relationnelles, caractérisés par la mise en place d'institutions internationales fondées sur un droit nouveau en pleine élaboration et l'idéologie universelle des Droits de l'homme, ratifiée par la quasi-totalité des Etats. Dans un monde où tout événement est immédiatement connu, l'étranger proche, l'échange généralisé, aucun isolat ne peut échapper à la vigilance et à la soif de compassion du téléspectateur, du touriste, de l'électeur. Un tel processus a accéléré le déclin des Etats, victimes des mêmes mises en causes que celles qui affectèrent les féodalités médiévales au moment de l'émergence de leur modèle. Soumis aux aléas du marché, contraint de se soumettre au droit et aux décisions d'instances supérieures, ONU, OUA, CEE, OCI..., comme aux pressions des hégémonies dominantes, ces institutions doivent par ailleurs, partager leur souveraineté avec des instances locales, des lobbies, des forces de contestation populaires spontanées que l'explosion de la "post-modernité" multiplie à l'infini.

Les Etats doivent respecter, en principe, les Droits de l'Homme, ceux-ci concernant chacun de leurs citoyens, lesquels peuvent de plus en plus avoir recours à des instances supérieures d'arbitrage pour faire valoir leurs intérêts. Cette crise de souveraineté est accentuée par la substitution à l'Etat de droit idéal, de régimes fondés sur des clientèles accusées de partialité, de corruption, de discrimination. C'est dans un tel contexte que se développent les poussées ethno-nationalitaires ou confessionnelles évoquées précédemment. Celles-ci se trouvent promues au rang de partenaires à part entière par les intervenants extérieurs, chaque Etat se trouvant cité à comparaitre sur des scènes ou devant des jurys où ses droits se trouvent contestés au profit de ceux de minorités qu'en d'autres temps il eut négligé ou réprimé avec vigueur.

Cette dynamique nouvelle est influencée par les processus modernes de médiatisation, lesquels la soumettent aux règles d'un marché médiatique "autonome". Attaché à susciter l'intérêt d'un public dont il lui faut constamment capter l'attention, le "quatrième pouvoir" cible ses médiations sur les événements susceptibles de capter l'émotion de ce public, en vue de distancer ses concurrents sur le marché de l'audimat ou de la publicité. Il lui faut à cet effet réduire les données à quelques traits spectaculaires, privilégier le nombre des victimes, dramatiser les situations, susciter une identification du spectateur ou du lecteur ou sa répulsion, donc forcer les caractères victimaires de l'agressé et les images persécutrices de l'agresseur, souvent sélectionnés l'un et l'autre en fonction de critères ambigus. Ce marché est particulièrement sensible au rapport des chiffres, des auditeurs comme des victimes, ou des fonds recueillis.

Sa volatilité, et l'inflation du contexte événementiel imposent des mises en scène relevant davantage du domaine de la publicité que de l'ordre des faits. Pour faire valoir sa cause, une communauté ou la minorité d'"entrepreneurs identitaires" qui s'emploient à la constituer, doit mobiliser ou rallier à son camp des tiers indifférents mais efficients, en alignant un maximum de victimes et de tragédies exceptionnelles. Ces acteurs doivent encore séduire les agents médiatiques ou le public par des voies indirectes en attirant, par exemple, l'attention des démarcheurs susceptibles de promouvoir une situation banale auprès des journalistes, des organisations ou des Etats susceptibles d'agir. De la défense des Droits de l'Homme à l'assistance "caritative"

Ces processus de restructuration de l'espace victimaire sont encore modifiés par le déploiement du marché caritatif contemporain, qui privilégie le coeur sur la raison, 
l'éthique sur le droit, la solidarité sur les frontières. Dans une conjoncture de retrait vis à vis de l'Etat-providence et de développement du mouvement associatif, ce nouveau marché bénéficie de l'arrivée sur la scène internationale de nouveaux entrepreneurs possédés par une passion victimaire nouvelle, assortie d'un souci rationnel d'efficacité. Reprenant à son compte l'élan missionnaire chrétien de l'ère pré-coloniale, ce mouvement a favorisé la création d'organisations non gouvernementales regroupant des médecins, des bénévoles, des cadres cléricaux ou syndicaux, appuyés par diverses églises, des organisations de défense des droits de l'Homme, des passionnés d'aventure, bientôt rejoints par un personnel médiatique et une classe politique en mal d'idéologie et d'électorat ou soucieuse de restaurer une image ternie par son impuissance à résoudre les problèmes économiques ou la corruption. Ainsi nait un "business humanitaire" capable d'influencer l'opinion grâce à l'usage de techniques publicitaires amplifiées par la demande des moyens de communication de masse en quête de publics. Le spectateur ou le lecteur redemandant du coeur, et donc du tragique, la presse et les écrans se sont concentrés sur les drames humains. Un "charity show" s'est développé, associant des vedettes du monde artistique, des publicistes, des entrepreneurs plus intéressés, quant à eux par les retombées de la charité que par le destin des victimes. Ainsi s'est développé un vaste marché caritatif, industrie de production et redistribution de dons impliquant des officines de démarchage des donateurs, traqués par les entreprises de marketing, des agences de collecte, de gestion de la manne caritative, de cheminement et de distribution du produit caritatif aux victimes ${ }^{17}$. La concurrence aidant, une part importante de l'argent ou des biens collectés se trouvant détournée vers les services de publicité, de gestion, de spéculations financières, le marché caritatif s'est engagé dans une mise en scène incessante des causes victimaires susceptible d'entretenir les flux oblatifs. Les entreprises "humanitaires" étant de plus en plus nombreuses, incapables de gérer seules des opérations toujours plus lourdes et soucieuses de privilégier leurs causes respectives, ce marché s'est rapidement dégradé. Tandis que les pouvoirs publics étaient à nouveau sollicités d'assister ce secteur privé, des procès retentissants révélant qu'une partie des dons ne parvenait jamais à leurs bénéficiaires supposés ont provoqués une méfiance croissante du public sollicité. Les mesures de contrôle prises par le législateur, dans un climat troublé par les pressions du mouvement associatif, se sont avérées peu efficaces. Pour relancer un processus en voie d'essoufflement, les entrepreneurs humanitaires ont tendance à privilégier les tragédies les plus spectaculaires. Un gigantesque appareillage regroupant associations, entreprises, services, institutions, médias, sociétés victimisées en concurrence, réseaux locaux parasitant le flux humanitaire, s'est ainsi déployé sur la planète, offrant de nouvelles ressources aux stratèges politiques. Car, le critère d'intervention demeurant le nombre des victimes, lequel résulte des confrontations armées, les communautés, ou du moins les entrepreneurs identitaires qui prétendent les représenter et animent leurs mobilisations, se doivent d'accroître leur body count dans le but de voir leurs causes promues sur la scène du charity business et, par son truchement, de la compassion humanitaire, aux dépens de concurrents tout aussi malheureux mais de façon moins spectaculaire.

Des Droits de l'Homme au droit des peuples

Une troisième facette de l'ordre "humanitaire " s'est déployée en direction d'une assistance aux peuples victimes de discriminations, de persécutions, voire d'opérations génocidaires. La situation victimaire de ces collectivités suscite à la fois l'attention des défenseurs des Droits de l'Homme, émus par les atteintes aux dits droits résultant des 
agressions qui les affectent et celle des associations caritatives désireuses de soulager leurs souffrances et d'empêcher les bourreaux d'agir, par pure humanité. Un des obstacles majeurs auquel se heurtent défenseurs des droits et secouristes réside dans les prétentions des Etats gérant les territoires où se déroulent les drames victimaires à contrôler leurs activités au nom d'un droit de souveraineté absolu. Tantôt, ces Etats refusent d'admettre les faits, minimisent le taux des victimes, nient les répressions et exactions. Tantôt, ils entendent s'imposer comme les uniques distributeurs de la manne humanitaire, prétention qui se prête à tous les détournements et aux opérations les plus machiavéliques. Ainsi, certains régimes mettent en scène les désastres qui frappent certaines fractions de leurs populations pour bénéficier de ressources nouvelles, affectées à d'autres destinations, quitte à multiplier le nombre des victimes par des opérations répressives massives.

Par ailleurs, chaque Etat est libre d'appliquer ou non les décisions votées par lui dans le cadre des institutions internationales dont il est membre. C'est contre de telles situations que certains promoteurs de la cause humanitaire se dressent aujourd'hui. Mais leur point d'appui, à savoir le "droit des peuples à disposer d'eux-mêmes" inscrit dans la charte des Nations Unies demeure réservé aux Nations-Etats déjà reconnues par les instances dont ils sont membres. Les risques de chaos universel que peut entraîner la mise en cause de ce principe, ainsi que les réticences des Etats nantis à réviser un statu quo qui leur est favorable ont conduit à en limiter l'application à des cas marginaux, tels ceux du Sahara occidental, de la Namibie ou du peuple palestinien. La notion de "peuple sans Etat" est d'ailleurs liée à un imaginaire ethno-politique qui n'est pas partagé par tous les sujets impliqués. En fait, l'émergence du principe politique du "droit des peuples" s'est greffé sur ceux plus neutres, du "droit à la différence", puis du "droit des minorités" qui se sont développés au sein des nations démocratiques à partir des années soixante sur la base du courant soixante-huitard et de l'émergence de l'idéologie d'inspiration anglo-saxonne et protestante du "politically correct". L'affirmative action nord-américaine, comme l'"Action positive" néerlandaise ou britannique, héritière, quant à elle, des politiques coloniales d'administration indirecte, prennent en charge les "minorités" victimes de discrimination: noirs, indiens, immigrés, femmes, homosexuels, etc, dans le but de favoriser leur intégration aux sociétés majoritaires en s'attaquant aux causes de leur marginalisation. Les atteintes au droit de minorités sont médiatisés. Des réglementations impératives sont promus par voie de lobbying et de décisions judiciaires. Ce courant a reçu une impulsion supplémentaire du fait d'un déplacement du messianisme prolétarien déjà évoqué sur les peuples opprimés du Tiers Monde, puis sur les "minorités nationales", avant d'être pris en charge par le mouvement humanitaire, ému par la multiplication des situations tragiques engendrées par le refus des minorités de plus en plus nombreuses de subir les discriminations et répressions résultant de leur situation au sein d'Etats se refusant à reconnaître leur "différence". Une telle situation engendre aujourd'hui les drames victimaires les plus exemplaires, marqués par des massacres, et exodes massifs, la multiplication de camps de réfugiés où des milliers d'exilés ne peuvent survivre que grâce à une assistance extérieure. L'émotion suscitée par de telles situations a permis de mettre en avant les revendications proprement politiques des communautés victimes. Tandis les acteurs humanitaires multipliaient les ingérences au sein des Etats concernés et que les associations pour les droits de l'homme traquaient les atteintes à la dignité ou à la vie des sujets victimisés, les représentants des communautés en lutte ont cherché à profiter de l'éclairage dont bénéficiait leur situation pour promouvoir 
leurs causes, au prix de sauts victimaires parfois importants. Tandis que les Etats mis en cause considéraient les "rebelles" comme des agents de déstabilisation favorisés par l'intérêt des médias et intervenants étrangers et s'efforçaient de les réduire au silence, les opérateurs caritatifs s'efforcent d'engager des stratégies nouvelles d'"accès aux victimes".

De l'accès aux victimes aux interventions humanitaires armées

A la croisée des courants de défense des droits de l'homme, de l'assistance caritative et du soutien des "minorités" martyres, le mouvement humanitaire a ainsi débouché sur une stratégie géopolitique fondée sur la promotion d'un ordre international gouverné par l'éthique qui l'animait. Ce grand dessein, reprenant à son compte le flambeau des croisades "civilisatrices" du XIXè siècle, s'est arrimé sur le môle du procès de Nuremberg, fondé sur un droit de transgression de la souveraineté des Etats coupables de "crimes contre l'humanité". Si les responsables de l'holocauste nazi étaient condamnés, la passivité des témoins de ces crimes, et au premier chef des organisations humanitaires, comme la Croix Rouge, se trouvait mise en question. Certains l'interprétaient comme une forme de complicité et surtout de non-assistance à personne en danger. Les décisions solennelles et autres résolutions des Nations Unies, bien que ratifiées par la quasi-totalité des Etats membres, demeurant sans effet au sein de la plupart d'entre eux, divers acteurs internationaux, aiguillonnés par les institutions humanitaires et une opinion publique de plus en plus informée, ont progressivement engagé des mesures mettant en cause la souveraineté des Etats coupables.

Tandis que les casques bleus multipliaient leurs interventions, des sanctions ont commencé à frapper les défaillances les plus graves. L'effort des organismes humanitaires privés s'est porté sur des actions d'infiltration au sein du dispositif national des pays en proie à des guerres civiles, au prix de certaines libertés avec le droit en vigueur: French doctors, convoyeurs ou distributeurs de vivres et de médicaments ont franchi clandestinement leurs frontières au profit de communautés rebelles. Dénonçant les victimisations dont elles étaient l'objet, cautionnant leur action, popularisant leurs causes auprès de l'opinion et multipliant les pressions sur leurs Etats ou les instances internationales, ils ont pesé de plus en plus sur les conjonctures locales, au grand dam des Etats contestés, ceux-ci les accusant de faire le jeu de leurs opposants et de favoriser leur déstabilisation sous prétexte de secourir les victimes, tandis que ces intervenants privés assuraient n'avoir aucune visée politique ou idéologique.

Ecrasés par l'ampleur des désastres, frustrés par les blocages opposés à leur action et prenant conscience du fait qu'il ne suffisait pas d'aider les victimes à survivre jusqu'au moment où les forces répressives se trouvaient en mesure de les éliminer, certains acteurs humanitaires ont accentué leurs pressions en vue de provoquer l'instauration, au besoin par la force, d'un ordre pacifique préventif d'hécatombes. Cette nouvelle stratégie exigeait l'élaboration de codifications juridiques internationales nouvelles. Les premières mesures prises à l'échelon des organisations internationales ont imposé la notion de "droit" ou de "devoir" d'ingérence, dont le principe de base était, selon l'expression du président François Mitterrand que "le devoir de non-ingérence s'arrête où naît le risque de non-assistance" ${ }^{18}$. Sur cette base, la France a fait prévaloir au sein des Nations Unies le principe d'une délimitation de "sanctuaires humanitaires" protégés par les forces internationales au sein d'Etats soumis à des situations de répression, les régimes au pouvoir se trouvant contraints de tolérer ces entorses à leur 
souveraineté19. La résolution 508 d'avril 1991 a avalisé cette pratique, permettant aux forces de divers Etats étrangers d'assumer des missions humanitaires armées au coeur d'un Irak où la poursuite des affrontements entre guérillas kurdes et armée répressive ne cessait, par ailleurs, d'accroître le nombre des victimes.

Dans la foulée, l'aggravation des affrontements opposants, au sein de l'ancienne Yougoslavie les forces serbes engagées dans une opération de "purification ethnique" aux résistances croate et bosniaque a bénéficié d'une médiatisation et d'actions d'ingérence humanitaire de grande ampleur, tandis que les pressions se multipliaient dans le but d'impliquer des puissances extérieures dans le conflit. Des casques bleus se sont entremis entre les belligérants avec pour mission de favoriser l'accès des secours humanitaires aux victimes. Ces efforts se sont heurtés aux réticences des Etats pressentis à s'engager plus avant, compte tenu des risques de victimisations susceptibles d'affecter les forces éventuelles d'intervention elles-mêmes et de la complexité de la situation régionale.

C'est le désastre somalien, dont la situation était moins inextricable et moins susceptible de produire un taux important de victimes au sein des forces intervenantes qui a servi de tremplin à une avancée du principe, non plus "d'ingérence", mais "d'intervention" (armée) humanitaire. Dans un climat préparé par l'intensification de la médiatisation des souffrances des victimes d'une situation chaotique, le ciblage de l'opinion sur ce pays et la proclamation de constats d'impuissance de la part des organisations humanitaires présentes, ainsi que de la force de protection des Nations Unies chargées en principe de permettre à celles-ci l'accès aux victimes, le vote de la résolution 794 du Conseil de Sécurité de l'ONU du 3 décembre 1992 a été salué comme l'acte de naissance d'un droit nouveau ${ }^{20}$. Cette résolution confiait, en effet, à l'imposante force d'intervention armée autorisée à intervenir dans ce pays la mission de favoriser le règlement politique de la situation politique locale, en sus de l'action de protection des opérations caritatives. Des divergences se sont toutefois exprimées entre les promoteurs de ce projet et divers acteurs politiques, militaires ou humanitaires inquiets des conséquences. Ces derniers ont évoqué des risques d'interférence de stratégies étrangères à la cause humanitaire, de ciblages sélectifs sur des foyers de victimisation sans portée politique ou victimaire gênante pour les intervenants, aux dépens de causes souvent plus préoccupantes mais plus difficiles à gérer politiquement, voire du caractère universel des Droits de l'Homme, les causes à risque risquant de sombrer dans une obscurité propice à tous les holocaustes. D'autres encore ont manifesté la crainte de voir les acteurs communautaires locaux intensifier leur production de victimes dans l'espoir de forcer l'attention des décideurs humanitaires puis, en deuxième détente, de susciter des interventions exclusivement politiques, de telles stratégies entraînant les réactions violentes des Etats ou acteurs menacés dans leurs intérêts ${ }^{21}$.

L'introduction dans le champ humanitaire du domaine des droits des peuples, fondé sur un principe exclusivement collectif, étranger et souvent opposable aux droits du sujet individuel introduit, en outre une confusion dont les effets demanderaient à être évalués. Sachant, en effet, que les affirmations communautaristes impliquent des sujets souvent indifférents au départ que leurs dirigeants s'emploient à entraîner, de façon plus ou moins volontaire, dans des situations débouchant sur leur propre victimisation, on peut s'interroger sur la liberté laissée aux individus. Le service d'une cause justifiant aux yeux des dirigeants d'une communauté en guerre leur assujettissement au devoir sacrificiel et la condamnation des "traîtres", ce type d'assistance ne consacrerait-il pas 
une victimisation contraire à leurs droits universels? Par ailleurs, l'extension du principe d'intervention humanitaire à des opérations musclées engagées dans un but très différent d'une mission de simple protection des organismes d'assistance, souhaitée par les tenants de l'imposition d'un nouvel ordre a-victimaire par la force ouvre une problématique délicate : on peut s'interroger, en premier lieu, sur la capacité ou la volonté des forces d'intervention ou de leurs supports d'intervenir sur tous les champs de bataille. Les exemples du Vietnam, du Liban ou de l'ex-Yougoslavie ont montré que les sociétés les plus engagées dans cette voie sont aussi les plus vulnérables à toute surenchère victimaire. On peut également s'inquiéter des risques de tension généralisée engendrés par une telle politique. Certains acteurs humanitaires ont manifesté leur crainte que des populations ainsi agressées, subissant un surcroît de victimisation des oeuvres des intervenants ou frustrées par ces dernières dans leurs aspirations, ne se dressent contre eux, les organisations caritatives étant même perçues comme les éclaireurs d'une nouvelle colonisation, comme aux temps précoloniaux ou la "croix" précédait le "pavillon". L'implication de tiers armés et motivés par des impulsions humanitaires risque en outre de déboucher sur un climat de surenchère victimaire généralisée : chaque communauté étant soucieuse de distancer ses rivales (dont la plupart lui sont inconnues) les seuils de victimisation "utiles" sont susceptibles de s'élever, tandis que les communautés les moins productives peuvent se voir impitoyablement éliminées de la scène, quelle que soit la valeur de la cause ou de l'oppression supportée. Il ne suffit d'ailleurs pas, pour une communauté donnée, de produire un nombre important de victimes tout en épargnant au maximum son adversaire afin de ne pas favoriser sa cotation. Il faut encore que ce sacrifice soit pris en compte par le marché médiatique, seul susceptible de lui conférer une valeur. Un autre effet pervers de la dérive évoquée peut être qu'une communauté victimisée incapable de consentir à sacrifier le nombre de ses membres nécessaires à la promotion de sa cause face à un adversaire exerçant une surenchère et capable de le faire impunément ou de façon silencieuse, est désavantagée sur le marché sacrificiel et donc vouée à une victimisation croissante, en l'absence d'alternative de dépassement de la logique qui la motive.

Jalons du positionnement humanitaire au sein du champ victimaire

La mise en scène progressive de ces nouvelles stratégies triangulaires s'est trouvée jalonnée par une série de "précédents". L'un des premiers est l'affaire du Biafra, nation sécessionniste née de la conviction des membres de l'ethnie igbo, implantée dans la région de l'est du Nigeria, d'être victimes d'un génocide de la part de peuples rivaux ${ }^{22}$. Après avoir été à l'avant-garde du mouvement nationaliste, les membres de cette ethnie entreprenante, dont la diaspora s'était diffusée dans l'ensemble de la fédération, se sont heurtés aux réactions de rejet de la part de populations d'accueil, celles-ci redoutant un hégémonisme igbo. Victimes de pogroms renouvelés, dans le nord du pays soumis à une aristocratie musulmane conservatrice, les émigrés sont rentrés en catastrophe au pays dans l'intention d'y tenir tête jusqu'au dernier à leurs agresseurs. L'Etat du Biafra qu'ils ont proclamé se fondait sur un imaginaire du martyre. Son drapeau était notamment rouge de la couleur du sang des martyrs et noir en signe de deuil. La conviction que ses adversaires souhaitaient l'exterminer, entretenue par une propagande intensive, a soutenu une résistance héroïque qui aurait fait plus d'un million de victimes. La nation rebelle a bénéficié d'un soutien médiatique, humanitaire et diplomatique inédit, plusieurs organisations caritatives ou chrétiennes soutenant une campagne mondiale en sa faveur. Les photos d'enfants biafrais décharnés ont fait le 
tour du monde. La victoire des forces fédérales, soutenues par les grandes puissances, ne s'est pas traduite, toutefois, par le bain de sang annoncé. Une réconciliation nationale bien conduite a permis la réintégration des «rebelles", tandis que la mémoire des victimes de la "guerre civile" a permis au régime du colonel Gowon de construire une nouvelle idéologie nationaliste.

Un second jalon a été le cas du Sahara occidental. Celui-ci s'est inscrit à l'origine dans le cadre de la décolonisation africaine puis, du fait de la main mise du Maroc sur cet ancien territoire espagnol, en novembre 1975, d'une résistance nationale à une agression extérieure. C'est à ce titre que la République arabe sahraouie démocratique (RASD) a été reconnue par 63 pays, ainsi que par l'OUA. Débouté de ses prétentions initiales sur un "Grand Maroc" étendu jusqu'au rives du Sahel, l'Etat chérifien s'est crispé sur ses revendications. De leur côté, les quelques intellectuels qui fondèrent le Front Polisario ne sont parvenus à rallier et armer leurs compatriotes nomades que grâce à l'aide de la Libye, puis de l'Algérie, devenue bientôt le véritable maître d'oeuvre de l'opération sahraouie, le support de son audience internationale et le sanctuaire d'où le Front Polisario pouvait lancer ses raids à l'intérieur du territoire national occupé et où il pouvait établir ses camps de réfugiés. Ce sont ces derniers qui ont suscité l'intérêt et l'intervention des organisations humanitaires, accompagnée d'une médiatisation systématique et de l'appui de nombreux partisans européens, se recrutant notamment au sein des classes politiques progressistes, tandis que les organisations pour la défense des Droits de l'Homme se mobilisaient pour la cause des prisonniers sahraouis détenus par le Maroc et victimes de traitements répressifs. Les victimes des combats ont été exaltées dans un but d'affermissement nationalitaire, sur la base du slogan: "toute la patrie ou le martyr" et, simultanément, d'attraction de l'intérêt de l'opinion internationale. Mais les appuis dont disposait le Maroc ont freiné l'action de l'OUA, puis de l'ONU, qui s'est entremise en vue de l'organisation d'un référendum local. Les combattants sahraouis se sont vus en outre sacrifiés par l'Algérie sur l'autel de la réconciliation maghrébine, tandis que le Maroc bénéficiait d'une politique d'ouverture, de la lassitude des exilés et du ralliement croissant de "rebelles" éminents, dont certains ont mis en cause les stratégies médiatiques, financières et d'encadrement des dirigeants du Front comme de leurs sponsors ${ }^{23}$.

Un pas de plus dans le positionnement des causes victimaires au sein du champ humanitaire a été franchi par les palestiniens des territoires occupés se dressant contre une domination expropriatrice et écrasante, conduite par une armée moderne, les mains nues, ou seulement armées de pierres. Venant en contrepoint de l'échec du mouvement armé de l'O.L.P., l'intifada a conféré une nouvelle audience à la cause d'un peuple martyr. Redoutant de perdre l'image victimaire sur laquelle il fondait sa légitimité aux yeux de ses supports occidentaux, et soucieux de donner de lui-même la figure d'Etat démocratique, l'Etat d'Israël se trouvait impuissant à opposer à la « révolte des pierres » une répression appelée par ses tenants les plus extrémistes. la cause du peuple palestinien, quelque peu ternie par les dérives terroristes de certains de ses partisans armés et handicapée par les supports dont jouissait l'Etat persécuteur, s'en est trouvée consolidée. Par ailleurs, l'intifada est devenu un modèle de résistance exemplaire des faibles dans le monde entier, des villes du Tiers Monde aux banlieues occidentales. Les médias et organisations humanitaires ont amplifié sa dimension victimaire aux dépens de celle d'Israël, ainsi contesté sur la scène de sa propre légitimité ${ }^{24}$. 
La question du Kurdistan a déjà été évoquée. Ayant obtenu, par décision du Congrès de Sèvres, en 1920, un territoire national indépendant, ce peuple de près de vingt millions de membres s'est trouvé dépouillé de celui-ci et partagé entre plusieurs Etats, dont chacun s'est employé à conduire une politique "d'intégration nationale", en réalité fondée sur l'hégémonie d'une autre ethnie: turque, arabe ou persane, niant son identité. Tandis que les Etats voisins s'employaient à manipuler leurs minorités kurdes respectives dans le but de déstabiliser leurs rivaux, des mouvements de sécession armée se sont heurtés, partout, à des répressions massives. La première guerre du Golfe, entre l'Irak et l'Iran, s'est traduite par des massacres de guérilleros et de civils kurdes des deux côtés de la frontière des deux pays engagés dans cette confrontation totale. La seconde guerre du Golfe a affecté plus encore le sort des kurdes irakiens, encouragés à se soulever contre les forces du régime de Bagdad au moment où la coalition victorieuse paraissait décidée à renverser le régime oppresseur. En fait, ces forces sont restées l'arme au pied tandis que la résistance kurde était l'objet d'une répression impitoyable, forçant des centaines de milliers de rescapés à un exode lourd d'effets victimaires supplémentaires. Les organisations humanitaires ont multiplié leurs interventions et leurs pressions sur les Etats de la coalition et les institutions internationales. Elles sont ainsi parvenues à faire voter la résolution 688 obligeant l'Etat souverain d'Irak à tolérer sur son territoire la constitution "d'enclaves humanitaires" protégées par des forces armées, alors même qu'à leurs lisières les combats entre les troupes répressives de Bagdad et les peshmergas continuaient à alimenter le marché victimaire. Les massacres dont étaient victimes, au sud, les masses chi'ites, bien que tout aussi considérables, n'ont pas bénéficié de la même sollicitude, tandis que les opérations répressives de l'armée turque contre les guérilleros du PKK, poursuivis jusqu'au sein du territoire irakien se trouvaient pour ainsi dire absoutes du fait du caractère terroriste de l'action de ce parti, de l'appartenance de la Turquie à la coalition et d'impératifs géopolitiques prédominants. La question kurde a néanmoins favorisé une importante avancée dans le domaine des intervention humanitaires armées.

Plus modeste dans ses dimensions, la question touareg est elle aussi exemplaire dans la mesure où l'on trouve à l'oeuvre la plupart des stratégies victimaires évoquées précédemment. Les nomades touaregs, qui n'ont jamais formé un peuple, sont traditionnellement divisés en multiples fractions et confédérations. Chassés d'Afrique du Nord, ces berbères se sont implantés au Sahara central, chassant devant eux les populations noires du Sahel, non sans multiplier les rezzous, les exactions, les captures et déportations d'esclaves, suscitant ainsi des ressentiments au sein des populations victimes. Après avoir tenu tête au conquérant français et subi des répressions multiples, ces "seigneurs du désert" se sont pliés à la règle coloniale, appauvris, repliés sur leur désert. Les "hommes bleus" sont entrés dans la légende coloniale. A l'heure des indépendances, ils se sont trouvés impliqués dans les projets sahariens de la France, lesquels impliquaient leur séparation des populations "négro-africaines" méridionales. Plus ou moins encouragés à affirmer leur indépendance à cet effet, ils se sont en fait trouvés partagés entre trois Etats, deux à dominante noire, dont les régimes nationalistes et progressistes leur reprochaient une certaine complaisance envers l'ancien colonisateur, leur penchant "tribalistes", leur répugnance à se plier aux projets de sédentarisation et aux partages frontaliers, leur indocilité, leur arrogance. Soumis à des encadrements tatillons et revanchards, les soumettant à des humiliations répétées, ils ont été frappés de plein fouet par les sécheresses des années soixante dix, qui les 
privaient de leurs troupeaux, les réduisant à une "clochardisation" douloureuse, au moment même ou l'exploitation des mines d'uranium saharien sur "leur" territoire enrichissait les élites sédentaires, sans retomber sur leur destin. Beaucoup de jeunes ont alors émigré en Libye, où le colonel Kadhafi, multipliant les appels au peuple touareg et dénonçant sa victimisation dans l'espoir de susciter la création d'un nouvel espace saharo-sahelien étendu (Etats Unis du Sahel), a enrôlé un certain nombre d'entre eux dans sa "légion islamique" opérant au Tchad et autres champs de batailles. Déçus par leur protecteur, nombre de ces émigrés sont rentrés au pays. Ces "chômeurs" (ishumar en langue tamachek), dont certains étaient formés à la guérilla, se sont engagés dans des opérations de vendetta à l'égard de régimes multipliant les vexations, déclenchant des répressions massives, provoquant des exodes, l'afflux de réfugiés dans les camps, la compassion des organisations caritatives et humanitaires, choquées par les détournements dont leurs aides étaient l'objet de la part d'intermédiaires et l'aggravation plus ou moins programmée du sort des derniers nomades.

Tandis que les combats s'accentuaient entre ishumar et forces de l'ordre de plus en plus répressives, une nouvelle élite touareg s'est affirmée, constituée de sujets scolarisés, urbanisés, en relation avec les organisations touristiques extérieures, dont les médias couvrant le "Paris-Dakar" et autres pôles de communication ouvert sur l'opinion internationale ${ }^{25}$. Des partis politiques se sont développés, s'appuyant sur cette opinion, sur les organisations humanitaires, sur des pays concernés par le destin d'une région troublée, dont la France et l'Algérie. Les processus de démocratisation engagés au Mali et au Niger en 1991-1992, suivis de près par Paris, ont favorisé la conclusion d'accords entre organisations touareg et Etats locaux, dont celui de Tamanrasset, en janvier 1991. Mais l'attitude des Conférences nationales, puis des nouveaux régimes de ces Etats, et surtout de leurs forces armées s'émancipant de leur contrôle et affirmant leur détermination d'écraser la "rébellion", mais aussi de venger leurs propres victimes, a ruiné l'espoir d'une fin des combats. Dans un climat de médiatisation bénéficiant de supports bien introduit dans les milieux des décideurs, la cause touareg est devenue un symbole. Mais les interventions espérées par les "entrepreneurs identitaires" tamacheks tardent à se produire du fait de la situation de la région, du déplacement des intérêts vers d'autres zones victimaires et de l'absence de volonté politique des décideurs en ce domaine.

Une étude plus exhaustive de la problématique évoquée devrait prendre en compte l'autre versant politico-confessionel du champ des stratégies victimaires. elle couvrirait des situations aussi tragiques que le partage indo-pakistanais, le conflit irlandais, la résistance afghane, la guerre civile du Soudan, les rebellions chi'ites d'Iran, d'Irak ou du Liban, la "révolution islamique" iranienne, les "jihads" islamistes, l'affrontement indien d'Ayodhya et même la question bosniaque telle qu'elle est perçue à travers le filtre religieux des pays et instances islamiques internationales, dont l'OCI, qui regroupe cinquante Etats. De telles situations mettent en scène autant de victimes, volontaires ou non, de stratégies humanitaires, d'ingérences ou d'interventions armées que le versant ethno-nationalitaire, avec lequel se confondent souvent ces mouvements. Peut-être découvrirait-on que le domaine confessionnel est plus opaque que le précédent, notamment du fait des ambiguïtés résultant de perspectives plus ou moins latentes selon lesquelles les droits de l'Homme s'arrêtent où commencent ceux de Dieu, ou des dieux. On trouverait également que les "entrepreneurs religieux" les plus enclin à prêcher la tolérance et l'amour du prochain ne sont pas sans éprouver une certaine indulgence, sinon une solidarité plus ou moins active pour leurs frères "martyrs", 
même engagés dans des opérations victimaires qu'ils réprouvent ${ }^{26}$. Ces milieux peuvent encore redouter qu'une gestion des questions confessionnelles ou réputées telles par des intervenants étrangers aux hiérarchies ne soient préjudiciables aux intérêts prosélytes ou communautaristes qu'ils soutiennent. Sur le terrain, les positions des populations engagées dans ses actions de "purification" est moins nuancée.

Retour du tragique, ou dérives de la modernité ?

L'inflation des productions victimaires qui se développe aujourd'hui dans le monde entier vient contrarier une vision "moderne" du monde qui l'exclut de ses projets planétaires et promeut le respect du sujet individuel, la solidarité, la rationalité, soit l'exclusion de la passion et du tragique du champ des relations humaines. Pour une telle vision, les dérives évoquées ne sont que des vestiges d'une ère barbare appelés à disparaître dans la nuit des temps obscurs. Mais la figure de la victime sur laquelle elle fonde son appréhension de ces violences est avant tout celle d'un sujet passif subissant une agression. Nous avons vu qu'une telle approche négligeait une autre face, essentielle, du processus en question, à savoir le sacrifice volontaire de sa vie par un sujet pris dans une problématique d'offrande, d'identification de quête de gloire. C'est sur cette figure tragique seulement qu'une communauté politique véritable peut se fonder, l'absence de martyrs potentiels suffisant à l'empêcher de s'affirmer. La première tâche d'un "entrepreneur identitaire" soucieux de constituer ou reconstituer une telle communauté est de revêtir cette image et d'insuffler la passion du sacrifice à une poignée d'adeptes constituant un premier arsenal victimaire. Il peut alors tenter de rallier la grande masse des sujets, souvent indifférents au départ, voire hostiles à son entreprise, qu'il espère mobiliser en une polis active. L'usage de premiers martyrs, suscitant des identifications en chaîne, des solidarités, des réactions de vindicte peut y parvenir en partie, notamment en déclenchant un cycle de provocation/répression riche en production victimaire aveugle impliquant progressivement les plus neutres.

Aujourd'hui, cependant, cet usage instrumental des victimes est bouleversé par l'inscription de telles problématiques au sein d'un espace nouveau, marqué par l'intervention de tiers peu concernés par les causes communautaires locales mais dont l'apparition peut en modifier radicalement les contours et la destinée. Or, ces tiers aux multiples visages sont avant tout sensibles au spectacle et au nombre des victimes produites, en fonction de motivations au demeurant très diverses: compassion, identification, culpabilité, profit, bénéfices politiques, idéologies... Le comptage des victimes positionne chaque communauté sur un marché soumis aux lois de l'offre et de la demande, de la concurrence, du démarchage, de la publicité, de la saturation. Pour être bien cotée à cette bourse des tragédies, une communauté militante doit aligner un nombre important de victimes, plus élevé que ses concurrentes connues ou non, qu'il s'agisse de morts, de blessés, d'exilés, d'affamés, tout en évitant d'accumuler les victimes chez ses adversaires de peur de voir ceux-ci se prévaloir de leurs "martyrs" pour améliorer leur indice. Encore convient-il que sa cause ne heurte pas de puissants intérêts capables d'influencer les metteurs en scènes de son martyre ou les intervenants, ou bien encore que ces derniers ne puissent escompter qu'un taux liminaire de victimes dans leurs rangs, étant donné le très faible niveau de leur propre vocation au "martyre". L'assujettissement à la loi des nombres peut également engendrer des effets pervers, l'accumulation des causes, les possibilités limitées d'intervention des tiers ou les stratégies des acteurs surdéterminant les tragédies les plus sanglantes. En une telle conjoncture, les impératifs d'une production victimaire accrue peuvent inciter des acteurs cyniques à accroître leur coefficient en engageant 
des actions suicidaires ou en amenant leurs adversaires par des actes de provocation calculée à multiplier les victimisations à leur encontre, en vue de susciter ou d'entretenir l'intérêt des journalistes, des acteurs humanitaires et des pays ou institutions susceptibles d'intervenir à leur profit. Un autre effet pervers du climat de la quantification peut être, au contraire, d'entraîner des opérations de victimisation des intervenants "neutres", dans le but de les décourager ou de les inciter à reporter leur attention sur des zones à moindre risque. En un tel cas, c'est le seuil de victimisation des organisations humanitaires qui décide du sort d'une population soumise à oppression.

De tels développements témoignent de l'insertion des recompositions tragiques évoquées dans ces lignes au sein d'une modernité où les coûts, évalués à une aune quantitative, comptent davantage que les valeurs qualitatives sur lesquelles se fondent en principe les causes communautaristes productrices de "martyrs" et les ingérences compassionnelles. La crise du marché victimaire engendrée par l'afflux des candidatures et l'essoufflement des tiers-intervenants risque ainsi d'accroître constamment la production des victimes, au prix d'une dévalorisation de la vie humaine supplémentaire, venant contrarier les valeurs humanitaires qui légitiment l'intervention de tiers.

Toutefois l'inflation que nous constatons peut ne correspondre qu'à une mode passagère ou à l'effet de circonstances ponctuelles liées à la crise mondiale des ressources et des échanges, des institutions politiques, des mobilisations idéologiques et surtout à un intérêt inédit et peut-être fragile des sociétés nanties pour le sort des laissés pour compte de la modernisation. Les effets de saturation de l'opinion, des impulsions caritatives, des organes médiatiques ou des oeuvres humanitaires, les prudences géopolitiques et les stratégies de diversion qui se développent peuvent se conjuguer pour provoquer un effondrement du marché victimaire. En un tel cas, la figure de la victime peut se trouver dévalorisée, dépouillée de toute utilité, voire exclue des conflits. Une autre alternative plus inquiétante est le risque qu'un retrait des tiersintervenants ne laisse place à une situation d'anomie retrouvant le lit des productions victimaires classiques ou, au contraire, à des dérives riches en productions victimaires gratuites émanant de bandes de "désespérés" dont la passion victimaire s'infléchirait vers des issues quasi-suicidaires.

\section{NOTES}

1. Girard (R.), La violence et le sacré, Paris, grasset, 1972 ; Le bouc émissaire, Paris, Grasset, 1982.

2. Nicolas (G.) « Cette loi qu'on prend entre ses mains. La pratique de l' « instant justice » sous la seconde République nigériane », Paris, Droit et Cultures, Nㅜㄱ, 1984 ; « Le phénomène de la vengeance dans une société sahelienne ", in R. Verdier, dir : La vengeance, vol 2, Paris, Cujas, 1986 ; « Le don rituel : face cachée de la modernité », Paris, Revue du Mauss, $\mathrm{N}^{\circ} 12,3^{\circ}$ trim. 1992.

3. Schmidt (C.), Théologie politique, Trad. J. L. Schlegel, Paris, Gallimard, 1991. 
4. Hegel (F.), Principes de la philosophie du droit, Paris, Gallimard, 1940.

5. Nicolas (G.), « Recompositions sacrificielles au Nigéria contemporain », in Archives européennes de sociologie, $\mathrm{N}^{\circ}$ XXXII, 1991.

6. Girard (R.), La violence et le sacré, opus. cit.

7. Rosolato (G), Le sacrifice, Paris, P.U.F., 1987.

8. Kepel (G.), La revanche de Dieu, Paris, Seuil, 1991.

9. Richard (Y.), L'islam chi'ite, Paris, Fayard, 1991.

10. Shari'ati (A.), On the sociology of Islam, Trad. H. Algar, Berkeley, Nizan Press, 1979.

11. Bataille (G.), Théorie de la religion, Paris, Gallimard, 1973.

12. Kepel (G.), Le prophète et pharaon, Paris, La découverte, 1984.

13. Le Monde, 4 décembre 1982.

14. Nicolas (G.), « Guerre sainte à Kano », in Politique africaine, Nº4, novembre 1981.

15. Etienne (B.), L'islamisme radical, Paris, Hachette, 1987. Cet auteur écrit notamment « Alors, Apocalypse now ? ...J'ai bien peur que face à l'ivresse de la mort, à la logique du camion chiite, à celle de l'Exocet, la rationalité stratégique soit impuissante...tout dépend maintenant de l'intensité de l'attente ", p316.

16. Roy (O.), L'échec de l'islam politique, Paris, Seuil, 1992.

17. Messien (F.), Les bons offices de la charité, Paris, Plon, 1981. Voir aussi Le Monde, des 11 et 12 octobre 1991, des 18 et 25 décembre 1991, 4 août 1991.

18. Déclaration à l'ouverture de la réunion de la CSCE sur les Droits de l'Homme, Paris, sorbonne, juin 1989, Cf. Le Monde, 1er juin 1989.

19. Fontaine (A.), « Les limites du droit des peuples », Le Monde, 5 octobre 1991

20. Le Monde, 5 décembre 1992.

21. Brosselet (H.), « Quand la politique se mêle de l'humanitaire », Le Monde, 13 janvier 1991. Domenach (J. M.), « Ingérence, violence et tolérance », Le Monde, 11 janvier 1992. Brauman (R.), Populations en danger. Médecins sans frontières, Paris, Hachette, 1992.

22. Madiebo (A. A.), The nigerian revolution and the civil war, Enugu, Fourth Dimension Publ., 1980. Nicolas (G.), « Dynamique agonistique d'une nation à polarisation variable », Cultures \& Conflits, $N^{\circ} 1$, hiver 1990-91. Nwanka (A.), The igbo leadership and the future of Nigeria, Enugu, Fourth Dimesion Publ., 1986.

23. Cf. l'interview d'Ibrahim Hakim, ancien ministre du Polisario, par Jeune Afrique, $\mathrm{N}^{\circ} 1659,22-28$ octobre 1992.

24. Morin (E.), « Juif : adjectif ou substantif », Le Monde, les 11 et 12 octobre 1992.

25. Dayak (M.), Touareg. La tragédie, Paris, J. C. Lattès, 1992.

26. Prince Sadruddin Aga Khan et Abdel Kader Chaderli, « La dernière croisade », Le Monde, 4 décembre 1992.

\section{RÉSUMÉS}

Parmi les violences contemporaines, les plus massives résultent des mobilisations de communautés ethno-nationalitaires ou politico-confessionnelles dressées contre des Etats répressifs ou des collectivités rivales. Ces mouvements débouchent sur une accumulation de victimes passives, il convient de prendre mesure du fait essentiel que ces communautés se 
fondent avant tout sur le sacrifice volontaire de leurs membres, sans lequel aucune d'elles ne pourrait s'affirmer. Le temps des "martyrs" est de retour. Toutefois, les stratégies sacrificielles d'aujourd'hui s'inscrivent dans un espace nouveau, marqué par l'intervention de tiers partenaires, spectateurs, juges, arbitres ou intervenants guidés par des mobiles de compassion, de justice ou de solidarité étrangers aux objectifs des communautés en conflit ; Du fait de cette évolution, la production de victimes est assujettie aux lois d'un marché spécifique, où les communautés concurrentes se trouvent cotées en fonction de critères quantitatifs. Les fluctuations de ce marché victimaire réagissent sur l'instrumentalisation des "martyrs".

Among contemporary outbreaks of violence, the greatest ones are the result of mobilisation of ethnic, political or religious communities against repressive governments or rival groups. Such movements cause many passive victims ; the very existence of the movements hinges on the willing self-sacrifice of their members : a return to the time of the martyrs. However today's sacrificial strategies are played out in a new environment in which others intervene : third parties, spectators, judges, mediators and those moved by compassion, justice and solidarity, and who are strangers to the conflict. This development has brought about a " market value of victims " ; groups are judged on quantitative criteria. The fluctuations of this market reproduce the instrumental utilisation of "martyrs".

\section{INDEX}

Mots-clés : Stratégie, victimes et victimisation 